\title{
Study of structural and dielectric properties of Nickel-doped $\mathrm{BaTiO}_{3}$ material
}

\author{
Hafes Ed-Dnoub ${ }^{1}{ }^{*}$, Ouafae El Ghadraoui ${ }^{1}$, Mohammed Zouhairi ${ }^{3}$, Ahmed Harrach ${ }^{1}$, Taj-dine \\ Lamcharfi $^{2}$ and El Houcine El Ghadraoui ${ }^{1}{ }^{*}$ \\ ${ }^{1}$ Chemistry of Condenser Matter Laboratory (LCMC), Faculty of Science and Technology, Sidi Mohamed Ben \\ Abdellah University, B.P. 2202, Fez, Morocco \\ ${ }^{2}$ Signals, Systems and Components Laboratory (LSSC), Faculty of Sciences and Technology, Sidi Mohamed \\ Ben Abdellah University, B.P. 2202, Fez, Morocco \\ ${ }^{3}$ Team of Materials, Membranes and Separation Processes, Moulay Ismail University, Faculty of Sciences of \\ Meknes, Morocco
}

\begin{abstract}
In this work, the effect of nickel (Ni) insertion on the structural and dielectric properties of $\mathrm{BaTiO}_{3}$ material was investigated. A series of powders of composition $\mathrm{Ba}_{1-\mathrm{x}} \mathrm{Ni}_{\mathrm{x}} \mathrm{TiO}_{3}(\mathrm{x}=0,0.05,0.1,0.15$ and 0.20$)$ were synthesized by solid method. The analysis by X-Ray Diffraction (XRD) shows that the obtained compounds crystallize in a phase of perovskite type. All the peaks are indexed in a phase of quadratic symmetry. Characterization by the Scanning Electron Microscope (SEM) indicates a heterogeneous microstructure of the grains. The study by spectroscopy of impedance in the frequency range $[500 \mathrm{~Hz}-1 \mathrm{MHz}]$ highlighted the effect of the nickel insertion on the transition temperature and the dielectric constant value.
\end{abstract}

Keywords: Perovskite; XRD; Dielectric; SEM; Spectroscopy.

\section{Introduction}

Perovskite-type materials are highly studied because of their relatively simple structure and the possibility of modifying their physicochemical characteristics by ionic substitutions on the different sites $\mathrm{A}$ and $\mathrm{B}$ of the $\mathrm{ABO}_{3}$ structure. These materials are of great interest because of the existence of a large number of ferroelectric phases. Moreover, these materials are likely to be applied in many uses such as microelectronics, FeRAM memories, microactuators or displacement sensors because of their effective dielectric properties ${ }^{1-4}$. The most studied perovskite-type materials are $\mathrm{BaTiO}_{3}, \mathrm{SrTiO}_{3}$, $\mathrm{PbTiO}_{3}, \mathrm{PbZr}_{\mathrm{x}} \mathrm{Ti}_{1-\mathrm{x}} \mathrm{O}_{3}(\mathrm{PZT})$ which have given rise to numerous studies concerning their properties, in particular, their ferroelectric character ${ }^{5-7}$.

It is well known that $\mathrm{BaTiO} 3$ is an important dielectric material that has excellent stable thermal properties and a high relative dielectric constant ${ }^{8-10}$. $\mathrm{BaTiO}_{3}$ has a general system Structure of type $\mathrm{ABO}_{3}$ where $A$ and $B$ are cations of different sizes, with the 6 cation fold coordinates $\mathrm{B}$ in the middle; the 12 cations fold coordinates $\mathrm{A}$ in the area and the anion, commonly oxygen, in the center of the face. We can think of the packaging of ions such as $\mathrm{A}$ and $\mathrm{O}$ ions forming tight ions together. $\mathrm{BaTiO}_{3}$ at a temperature

*Corresponding author: Hafes Ed-Dnoub

E-mail adresse: hafes.eddnoub@usmba.ac.ma DOI: http://dx.doi.org/10.13171/mjc8319051802hed below $130^{\circ} \mathrm{C}$ is transformed from the tetragonal phase to a cubic phase ${ }^{11}$. $\mathrm{BaTiO}_{3}$ can also exist in the orthorhombic phase at a temperature of $0^{\circ} \mathrm{C}$, in the rhombohedral phase below $-90^{\circ} \mathrm{C}, \mathrm{BaTiO}_{3}$ exists in the hexagonal phase above $1460^{\circ} \mathrm{C}$. Although the primitive cube is the idealized structure, the differences in radius between cations $\mathrm{A}$ and $\mathrm{B}$ can modify the structure at several different so-called distortions, whose inclination is most frequent. With the inclination of perovskite, the octahedron $\mathrm{BO}_{6}$ twists. Along one or more axes to accommodate the difference. The ferroelectric properties of $\mathrm{ABO}_{3}$ type ceramic perovskite (here barium titanate) can be effectively controlled by doping using different doping elements ${ }^{12-15}$. Up to now, researchers have shown strong interest in optimizing its more efficient application. Doping is of fundamental importance in controlling the crystallographic phase and modifying electronic properties. The ferroelectric properties of $\mathrm{ABO}_{3}$ type perovskite ceramic (in this study: Barium Titanate) could be efficiently controlled by doping with different elements ${ }^{16-19}$. A variety of different dopants can be introduced into the $\mathrm{BaTiO}_{3}$ network. $\mathrm{Ni}$ was chosen in this study as it replaces the $\mathrm{Ba}$ ion, and oxygen voids can be created to compensate for the charge. Although the valency of the $\mathrm{Ni}$ ion is the same as that of the $\mathrm{Ba}$ ion. The ionic radii of $\mathrm{Ni}^{2+}$ $\left(\mathrm{r}_{6}{ }^{2+}=0.69 \AA\right)$ is less than both the ions

Received February 10, 2019

Accepted April 11, 2019

Published May 18, 2019 
$\mathrm{Ba}^{2+}\left(\mathrm{r}_{6}{ }^{2+}=1.35 \AA\right)$ and $\mathrm{Ti}^{4+}\left(\mathrm{r}_{6}{ }^{4+}=0.61 \AA\right)$ and hence it can occupy both A and B sites.

This work aims to study the effect of the insertion of a transition metal $\left(\mathrm{Ni}^{2+}\right)$ in the matrix of BT. A series of composition $\mathrm{Ba}_{1-\mathrm{x}} \mathrm{Ni}_{\mathrm{x}} \mathrm{TiO}_{3}(\mathrm{x}=0$, $0.05,0.1,0.15$ and 0.20 ) was synthesized by solidstate reaction method. The powders were characterized by X-ray diffraction, scanning electron microscopy, and dielectric measurements. The experimental results show the influence of nickel insertion into the BT structure on the various physicochemical properties of the obtained material.

\section{Experimental}

Samples of $\mathrm{Ba}_{1-\mathrm{x}} \mathrm{Ni}_{\mathrm{x}} \mathrm{TiO}_{3}$ composition $(\mathrm{x}=0$, $0.05,0.1,0.15$ and 0.2 ) were prepared by solid phase synthesis method at $1000{ }^{\circ} \mathrm{C}$ according to the following reaction:

$$
(1-\mathrm{x}) \mathrm{BaO}+\mathrm{xNiO}+\mathrm{TiO}_{2} \longrightarrow \mathrm{Ba}_{1-\mathrm{x}} \mathrm{Ni}_{\mathrm{x}} \mathrm{TiO}_{3}
$$

The starting materials are taken in stoichiometric quantities. The mixture is then ground and homogenized for one and a half hours in a porcelain mortar. The purpose of this operation is to reduce the particle size and promote homogeneity of the mixture. The mixture is then subjected to chamotte at $400^{\circ} \mathrm{C}$ for 3 hours with a furnace temperature increase of $5^{\circ} \mathrm{C} / \mathrm{min}$. The powders are recovered and undergo another grinding and homogenization for one hour. The resulting product is then calcined at $1000^{\circ} \mathrm{C}$ for four hours, with a temperature rise of $5^{\circ} \mathrm{C} / \mathrm{min}$. After removing the product from the oven, another grinding is carried out for 30 minutes.

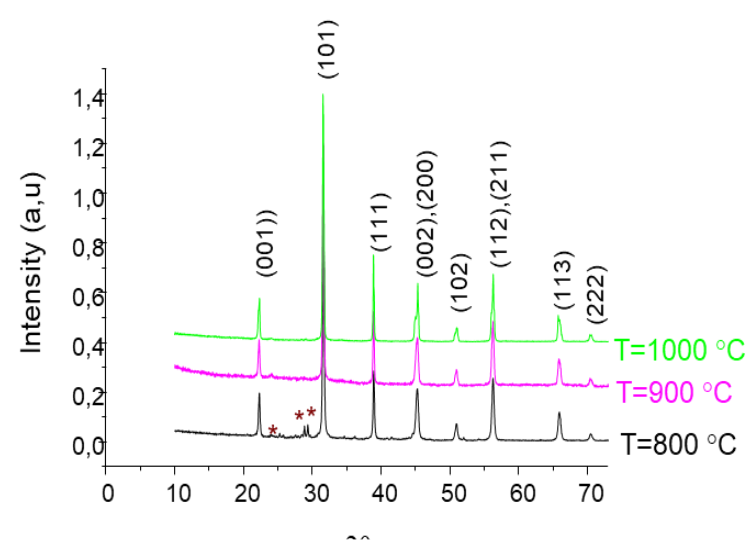

Figure 2. XRD patterns of BT prepared by solid state at 800,900 and $1000{ }^{\circ} \mathrm{C}$

Fig.4 shows the XRD spectra of $\mathrm{Ba}_{1-\mathrm{x}} \mathrm{Ni}_{\mathrm{x}} \mathrm{TiO}_{3}$ compounds ( $\mathrm{x}=0,0.05,0.1,0.15$ and 0.20$)$ calcined at $1000^{\circ} \mathrm{C}$ for 4 hours. The compounds obtained are isotype to that of pure BT. A slight variation of the parameters a and $\mathbf{c}$ of mesh (Table 1). No phase change was observed with the insertion of $\mathrm{Ni}$ in the

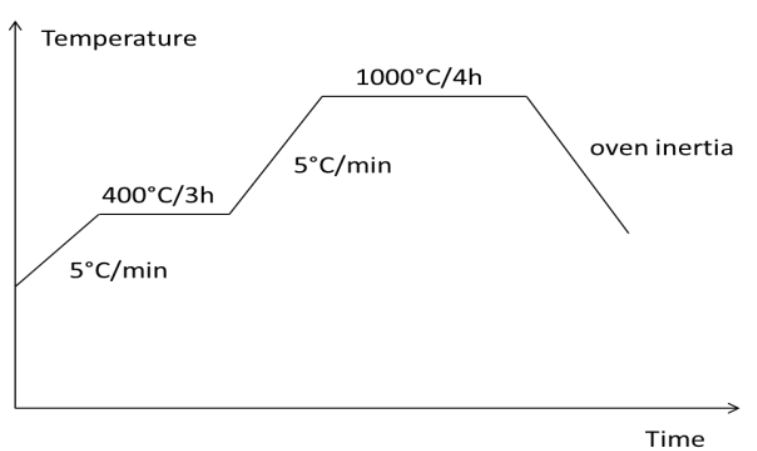

Figure 1. The cycle of calcination of $\mathrm{BN}_{\mathrm{x}} \mathrm{T}$ powders

\section{Results and discussion}

\section{X-ray diffraction analysis}

Fig. 2 shows BT X-ray spectra using X'Pert PRO Philips diffractometer (Philips Japan, Ltd, Japan), equipped with $\mathrm{CuK} \alpha$ radiation $(\lambda=1.5406 \AA)$. Bulk chemical composition was determined using an X-ray fluorescence (XRF) in a Bruker S4 Pioneer spectrometer (Bruker AXS GmbH Karlsruhe, Germany) prepared by a solid method at different calcination temperatures. The perovskite phase appears from $800{ }^{\circ} \mathrm{C}$, and it is obtained pure at $900{ }^{\circ} \mathrm{C}$. All the rays of the spectrum are indexed in a phase of cubic symmetry. When the calcination temperature increases $\left(\mathrm{T}=1000{ }^{\circ} \mathrm{C}\right)$, the separation of the two peaks (002) and (200) is observed Fig. 3, these peaks are characteristics of the quadratic symmetry which shows a transition to the quadratic phase as a function of temperature ${ }^{20}$.

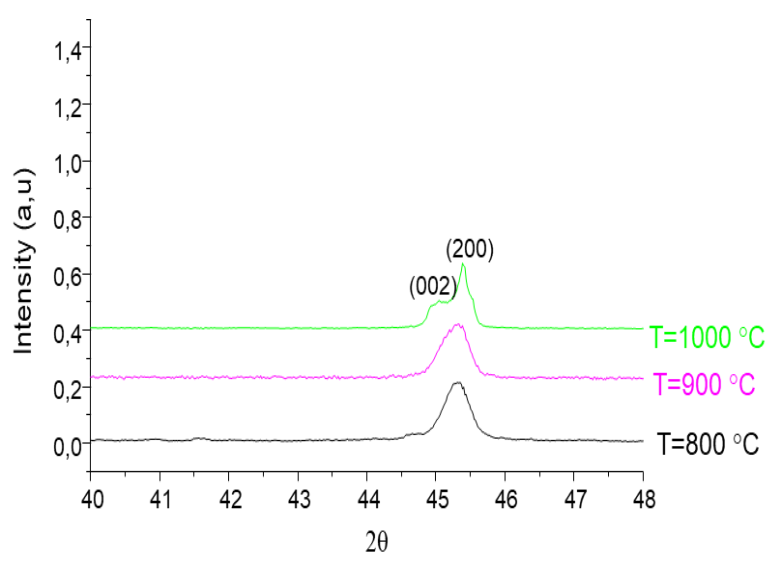

Figure 3. Peak zoom (200) in the range of $\left[40^{\circ}-50^{\circ}\right]$

matrix of BT, and these results are in agreement with the results of the recent works of Yogeswar Kumar $^{21}$. For $\mathrm{Ni}$ percentages of less than $20 \%$, $\mathrm{Ba}_{1-\mathrm{x}} \mathrm{Ni}_{\mathrm{x}} \mathrm{TiO}_{3}$ compounds are isotype to that of $\mathrm{BT}$. However, beyond $25 \%$, there is the appearance of micro-phases. 


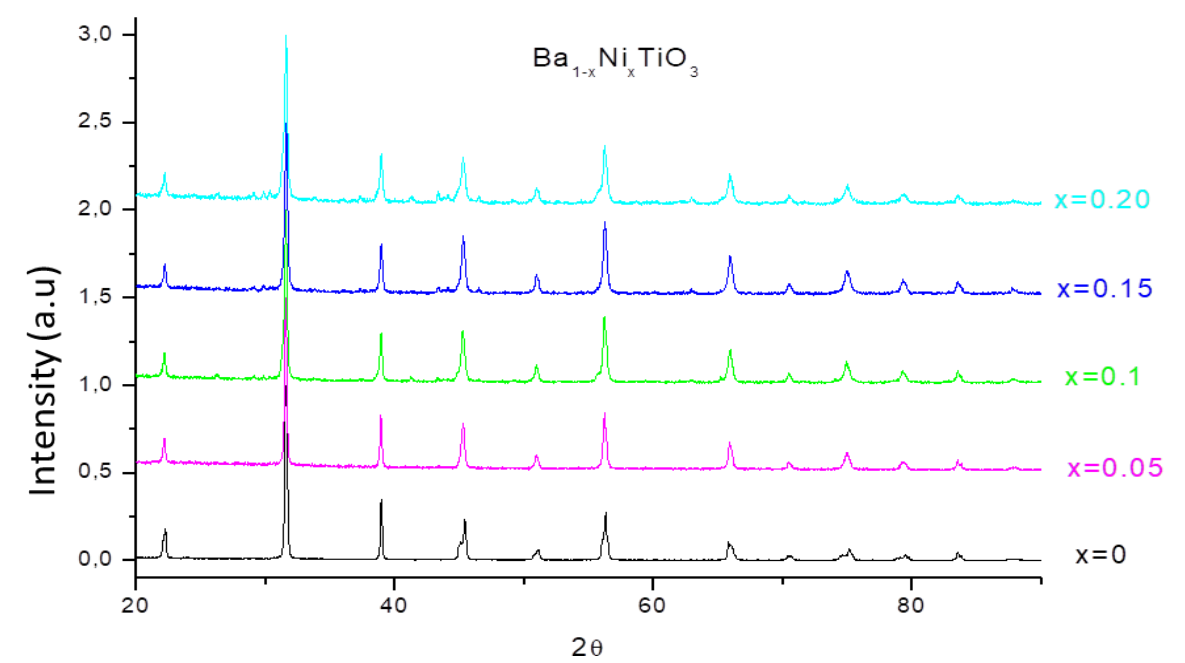

Figure 4. X-ray pattern of $\mathrm{Ba}_{1-\mathrm{x}} \mathrm{Ni}_{\mathrm{x}} \mathrm{TiO}_{3}$ powders calcined at $1000{ }^{\circ} \mathrm{C} / 4 \mathrm{~h}$

Table 1. Parameters, c/a ratio and volume of the mesh of BNT elaborated by the solid state at $1000^{\circ} \mathrm{C}$ during $4 \mathrm{~h}$.

\begin{tabular}{|l|l|l|l|l|}
\hline $\mathbf{B a}_{\mathbf{1 - x}} \mathbf{N i}_{\mathbf{x}} \mathbf{T i O 3}$ & $\mathbf{c}$ & $\mathbf{a}$ & \multicolumn{1}{|c|}{$\mathbf{c} / \mathbf{a}$} & Cell volume \\
\hline $\mathbf{X}=\mathbf{0}$ & 4.0209 & 3.9983 & 1.00565 & 64.2797 \\
\hline $\mathbf{X}=\mathbf{0 . 0 5}$ & 4.0138 & 4.00137 & 1.003106 & 64.2648 \\
\hline $\mathbf{X}=\mathbf{0 . 1}$ & 4.01369 & 4.00228 & 1.00285 & 64.2923 \\
\hline $\mathbf{X}=\mathbf{0 . 1 5}$ & 4.01312 & 4.003715 & 1.00235 & 64.3292 \\
\hline $\mathbf{X}=\mathbf{0 . 2 0}$ & 4.01291 & 4.00442 & 1.00212 & 64.3485 \\
\hline
\end{tabular}

\section{SEM analysis}

Fig.5 shows the SEM images (SEM, Phenom ProX with EDS detector (Phenom-World BV, Netherlands)) obtained for the sintered pellets of BNxT compounds at $1000{ }^{\circ} \mathrm{C}$ during 4 hours. For BT $(\mathrm{x}=0)$, the grains formed have a relatively

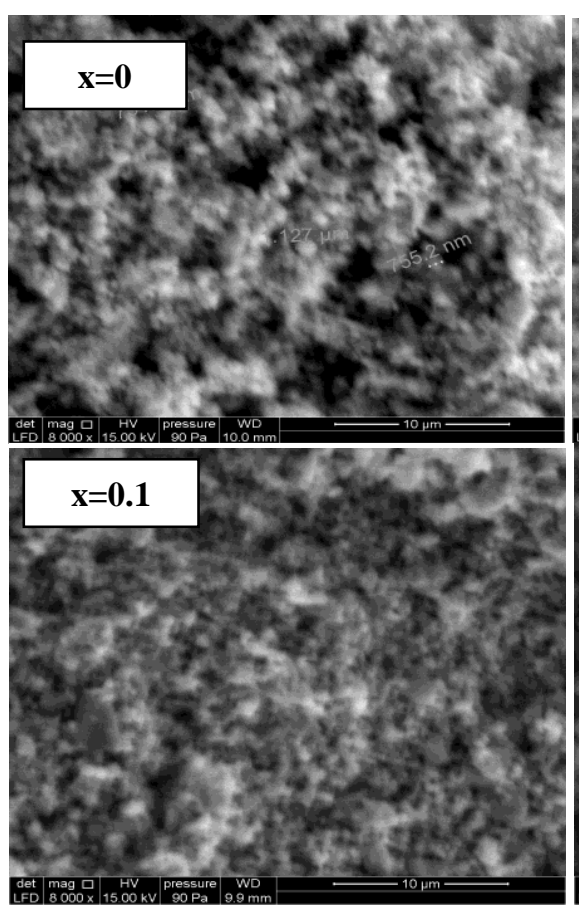

homogeneous and regular size with a quasi-spherical shape. The insertion of nickel affects the shape of the grains and their distribution, which becomes heterogeneous. Also, the average size of the grains decreases when the nickel level increases: $1.127 \mu \mathrm{m}$ for pure BT and $0.632 \mu \mathrm{m}$ when the nickel rate rises to $\mathrm{x}=0.15$.

Figure 5. SEM images of $\mathrm{BN}_{\mathrm{x}} \mathrm{T}$ ceramics sintered at $1000{ }^{\circ} \mathrm{C}(4 \mathrm{~h})$ 


\section{Dielectric measurements}

Fig.6 shows the dielectric constant evolution of $\mathrm{BN}_{\mathrm{x}} \mathrm{T}$ ceramics as a function of the temperature at different frequencies $[1 \mathrm{KHz}-1 \mathrm{MHz}]$. It is observed for all the ceramics that when the temperature increases, the dielectric constant regularly rises, after that, it increases sharply near the transition temperature. It reaches the maximum at this temperature and then declines rapidly. The transition temperature is independent of the frequency.

The BT doped with nickel allows the enhancement of dielectric constant value and the reduction of the transition temperature. It also widens the transition peak, which induces the stability of the materials.
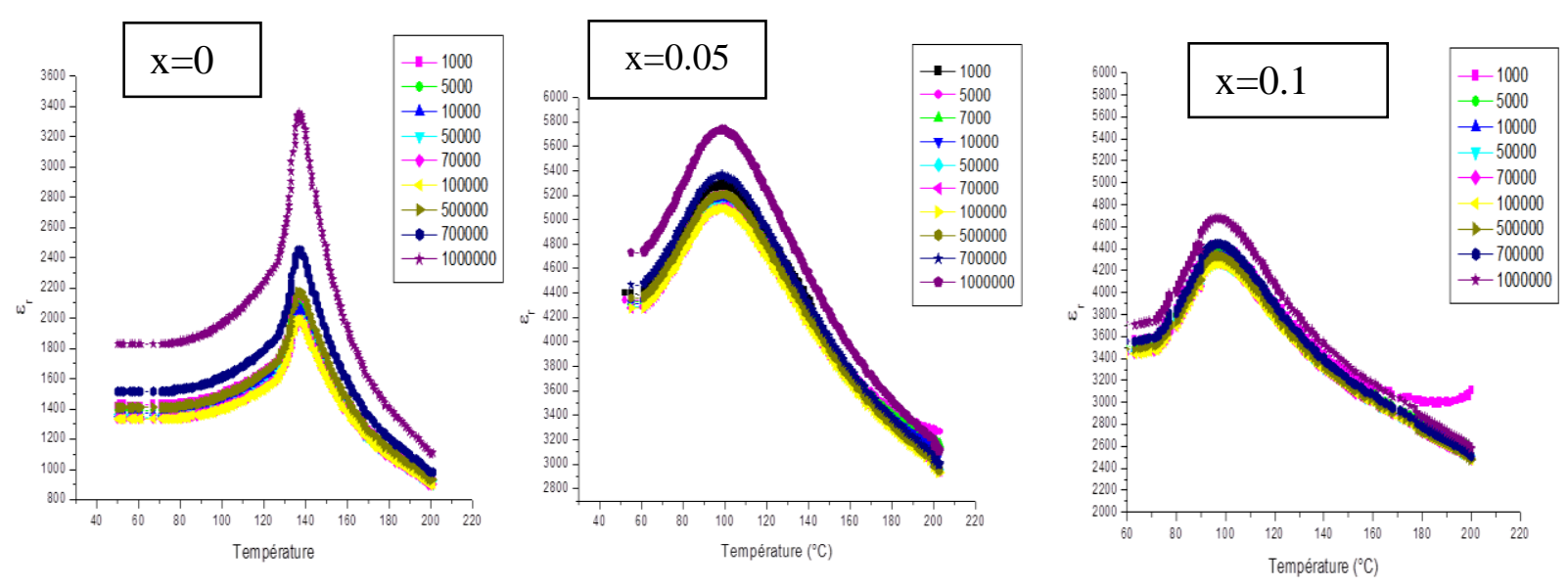

Figure 6. The dielectric constant evolution of $\mathrm{BN}_{\mathrm{x}} \mathrm{T}$ compounds sintered at $1000{ }^{\circ} \mathrm{C}$ for $4 \mathrm{~h}$ as a function of temperature at different frequencies

Fig. 7 shows the variation of the dielectric losses as a function of the temperature for a frequency of 1Mhz. The dielectric losses pass through a maximum at the transition temperatures. However, this maximum decreased when nickel is introduced. The values of the maximum dielectric losses are shown in Table 2 .
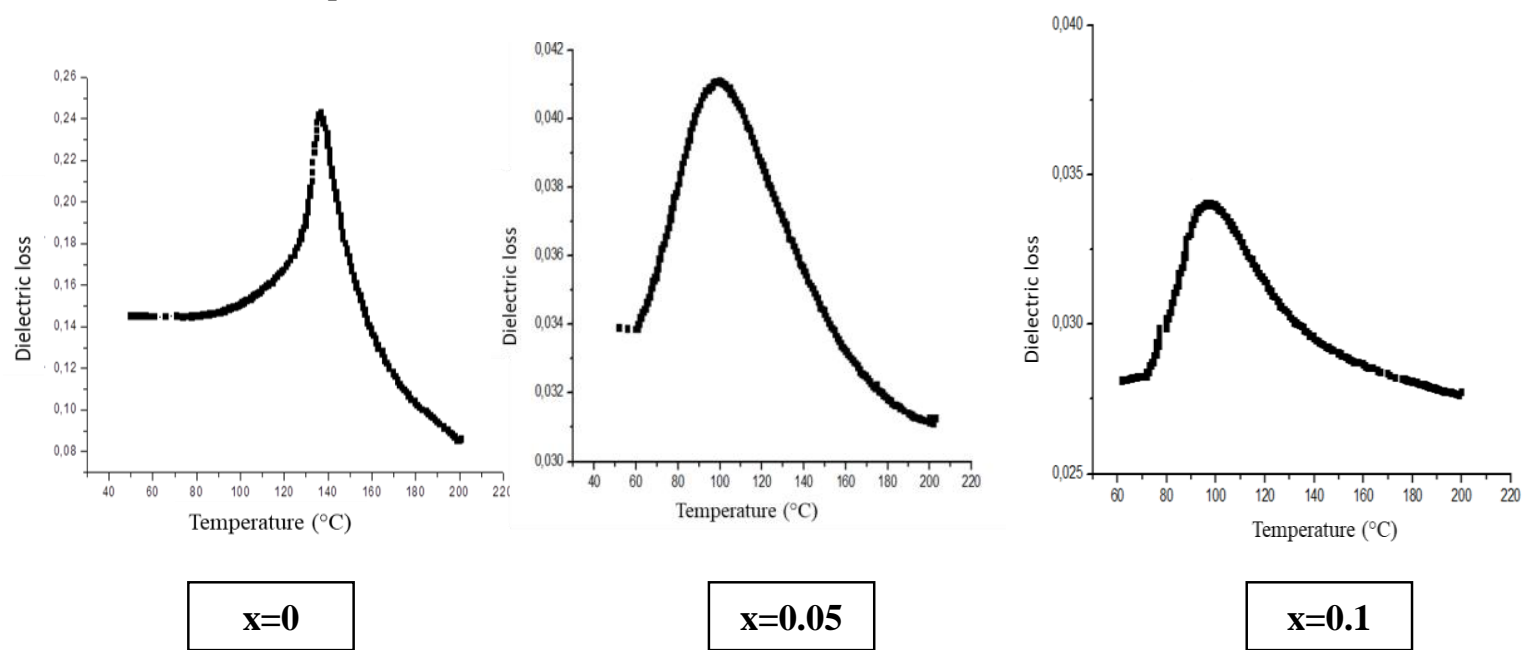

Figure 7. Dielectric losses evolution of $\mathrm{BN}_{\mathrm{x}} \mathrm{T}$ compounds as a function of temperature at a frequency of $1 \mathrm{MHz}$

Table 2. The $T g \&_{\max }$ values of the $\mathrm{BN}_{\mathrm{x}} \mathrm{T}$ compounds at a frequency of $1 \mathrm{MHz}$.

\begin{tabular}{|c|c|c|c|}
\hline $\mathbf{B a}_{1-\mathbf{x}} \mathbf{N i}_{\mathbf{X}} \mathbf{T i O}_{\mathbf{3}}$ & $\mathbf{x = 0}$ & $\mathbf{x}=\mathbf{0 . 0 5}$ & $\mathbf{x = 0 . 1}$ \\
\hline $\mathbf{T g} \boldsymbol{\&}_{\max }$ & 0.245 & 0.0411 & 0.037 \\
\hline
\end{tabular}

Fig.8 illustrates the ferroelectric behavior of the $\mathrm{BN}_{\mathrm{x}} \mathrm{T}$ compounds according to the modified
Uchino's law ${ }^{22}$, which is a straight line of the following equation:

$$
\left.\operatorname{Ln}\left[\left(\varepsilon_{\max } / \varepsilon_{\mathrm{r}}\right)-1\right)\right]=\gamma \ln [\mathrm{T}-\mathrm{Tm}]-\gamma \operatorname{Ln}(2 \delta)
$$

The critical exponent $\gamma$ is an empirical coefficient that describes the diffuse nature of the transition: 
$\gamma=1$ for a classical transition;

$1<\gamma<2$ for a diffuse transition;

$\gamma=2$ for a relaxor or diffuse ferroelectric;

$\delta$ : it informs on the degree of the peak spreading.

This diffuse character could be explained by the existence of polar microregions in the paraelectric phase at a temperature higher than $\mathrm{Tm}^{23}$.

Fig. 8 shows that the experimental points of $\mathrm{BN}_{\mathrm{x}} \mathrm{T}$ compounds are aligned well on a straight line, indicating that these compounds follow well the modified power law, which theoretical approach allows the determination of the coefficient $\gamma$ that measures the deviation degree of the thermal behavior compared to the Curie-Weiss standard law. The found values of $\gamma$ and $\delta$ are reported in Table 4 .

It is observed that the insertion of nickel increases the value of $\gamma$. In other words, the insertion of nickel leads to the diffuse character of $\mathrm{BN}_{\mathrm{x}} \mathrm{T}$
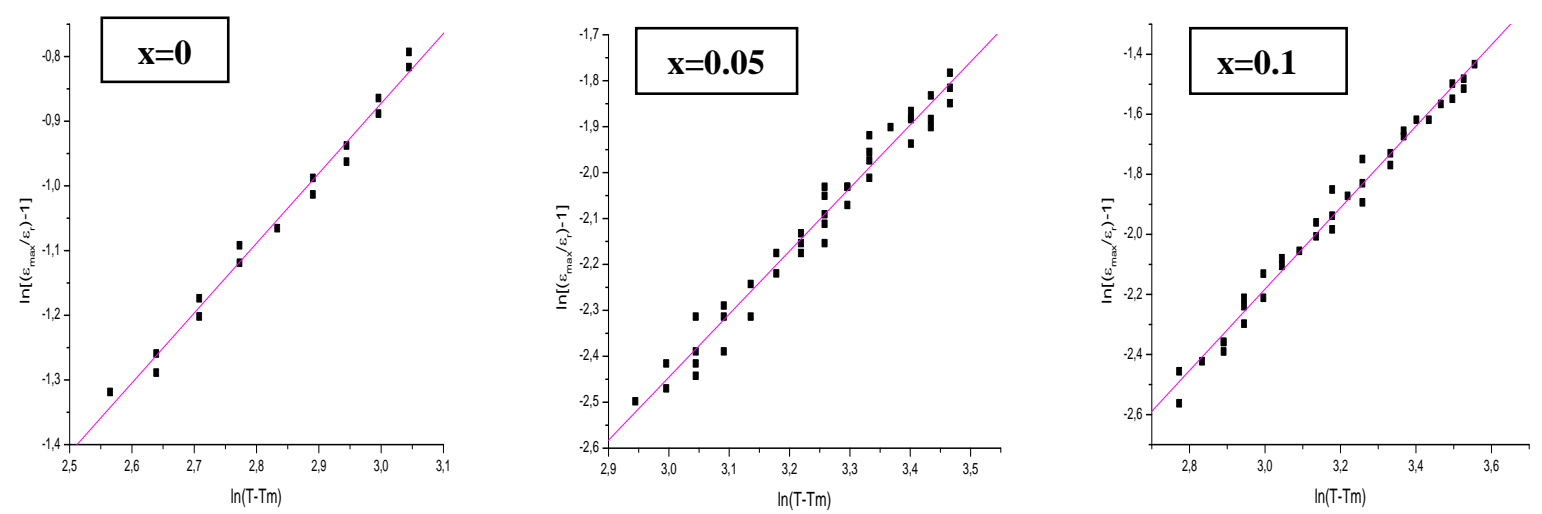

Figure 8. Evolution of Uchino law of the $\mathrm{BN}_{\mathrm{x}} \mathrm{T}$ compounds in the para-electric domain $(\mathrm{T}>\mathrm{Tm})$ at $1 \mathrm{KHz}$

Table 3. $\gamma$ and $\delta$ values at $1 \mathrm{KHz}$.

\begin{tabular}{|c|c|c|c|}
\hline $\mathbf{B a}_{1-\mathbf{x}} \mathbf{N i}_{\mathbf{x}} \mathbf{T i O}_{\mathbf{3}}$ & $\mathrm{x}=0$ & $\mathrm{x}=0.05$ & $\mathrm{x}=0.1$ \\
\hline $\boldsymbol{\gamma}$ & 1.08 & 1.37 & 1.35 \\
\hline $\boldsymbol{\delta}$ & 22.46 & 59.55 & 51.25 \\
\hline
\end{tabular}

\section{Conclusion}

The results obtained by X-ray diffraction on ceramics calcined at $1000{ }^{\circ} \mathrm{C}$ show that the powders crystallize well in the pure perovskite phase and the insertion of $\mathrm{Ni}$ in the matrix of $\mathrm{BT}$ produced no phase change. The SEM images show that nickel doping reduces the size of grains and affects their shapes. The dielectric characterization shows that the insertion of $\mathrm{Ni}$ in the matrix of BT allows widening the transition peak which induces stability of the materials, decreases the transition temperature and dielectric losses, and enhances the maximum value of the dielectric constant $\varepsilon_{\mathrm{r}}$.

\section{Acknowledgements}

The author would like to thank Signals, Systems and Components Laboratory (LSSC) for their help in characterizing the materials, technical assistance also their helpful discussions.

\section{References}

1- W.D. Maison, R. Kleeberg, R.B. Heimann, S. Phanichphant, Size-controllable barium titanate nanopowder synthesized via the onepot solvothermal route in a mixed solvent, J Eur Ceram Soc, 2003, 23, 127.

2- J.S. Obhi, A. Patel, Integration of sol-gel derived PZT with SOS technology, Integr Ferroelectric, 1994, 5, 155.

3- J.F. Scott, D. Galt, J.C. Price, J.A. Beall, R.H. Ono, C.A. Paz de Araujo, L.D. Mc Millan, Identification of passive layer in ferroelectric thin films from their switching parameters, Integr Ferroelectric, 1995, 189.

4- M.A. Mohiddon, P. Goel, K.L. Yadav, M. Kumar, P.K. Yadav, Effect of Ni doping on structural and dielectric properties of BaTiO3, Indian J Eng Mater Sci, 2007, 14, 64.

5- M. Zouhairi, H. Bali, O. El Ghadraoui, T. Lamcharfi, A. Elbasset, Synthesis and Pysico-Chemical Characterization of Perovskite Ceramics System PFN-PMN, IJCRR, 2015, 7, 22474-22477.

6- M. Zouhairi, O. Elghadraoui, H. Bali, T. Lamcharfi, F Abdi, L. Mrharrab, Synthesis and structural characterizations of hydrothermally processed $\mathrm{Pb}_{1-\mathrm{x}} \mathrm{La}_{\mathrm{x}} \mathrm{Ti}_{1-\mathrm{x} / 4} \mathrm{O}_{3}$ ceramic powders, Phys. Chem. News, 2014, 72, 42-48.

7- A. Elbasset, F. Abdi, T. Lamcharfi, S. Sayouri, M. Aillerie, Synthesis and Characterization of 
Strontium-Doped Barium Titanate Ceramics, I RE PHY, 2013, 7, 1971-680X.

8- D. Shan, Y.F. Qu, J.J. Song, Dielectric properties and substitution preference of yttrium doped barium zirconium titanate ceramics, Solid State Commun, 2007, 141, 65-68.

9- (a) P.K. Roya, J. Bera, Mater, Study on electromagnetic properties of $\mathrm{MgCuZn}$ ferrite/ $\mathrm{BaTiO}_{3}$ composites Chem. Phys, 2012, 132 (2-3), 354-357. (b) G.M. Keith, M.J. Rampling, K. Sarma, Mc.N. Alford, D.C. Sinclair, J Eur Ceram Soc, 2004, 24, 1721.

10- Y.C. Qing, W.C. Zhou, F. Luo, D.M. Zhu, Optimization of electromagnetic matching of carbonyl iron/BaTiO 3 composites for microwave absorption, J. Magn. Magn. Mater, 2011, 323, 600-606.

11- G.M. Keith, M.J. Rampling, K. Sarma, Mc. N. Alford, D.C. Sinclair, An atomistic study into the defect chemistry of hexagonal barium titanate, J Eur Ceram Soc, 2004, 24,1721.

12- Jona F \& Shirane G, Single-Crystal Ferroelectrics: Fundamental Physical and Electronic Properties Ferroelectric Crystal (Dover Publication, New York), 1993.

13- P. Goel, K.L. Yadav, A.R. James, Double doping effect on the structural and dielectric properties of PZT ceramics J Phys D: Appl Phys, 2004, 37, 3174.

14- P. Goel, K.L. Yadav, Structural and optical properties of Ag-doped copper oxide thin films on polyethylene napthalate substrate prepared by low-temperature microwave annealing $\mathrm{J}$ Mater Sci, 2007, 42, 3928.

15- M. A Mohiddon, K.L. Yadav, Domain Reorientation Dynamics of Sol-Gel Derived Strontium Doped PLZT (8/65/35) J Sol-Gel Sci Technol, 2009, 49, 88.
16- A Elbasset, S Sayouri S, F Abdi, T Lamcharfi, L Mrharrab, Complex impedance, dielectric relaxation and electrical conductivity studies of $\mathrm{Ba}_{1-\mathrm{x}} \mathrm{Sr}_{\mathrm{x}} \mathrm{TiO}_{3}$ ceramics, IOP Conf. Series: Mater Sci Eng, 2017, 186, 012018.

17- C. Y. Chang, W. N. Wang, C. Y. Huang, Effect of $\mathrm{MgO}$ and $\mathrm{Y}_{2} \mathrm{O}_{3}$ Doping on the Formation of Core-Shell Structure in $\mathrm{BaTiO}_{3}$ Ceramics, J. Am. Ceram. Soc., 2013, 96, 2570-2576.

18- M. B. Smith, K. Page, T. Siegrist, P. L. Redmond, E. C. Walter, R. Seshadri, L. E. Brus, M. L. Steigerwald, Crystal Structure and the Paraelectric-to-Ferroelectric Phase Transition of Nanoscale $\mathrm{BaTiO}_{3}$, J. Am. Chem. Soc., 2008, 130, 6955-6963.

19- F. Maldonado, S. Jácome, A. Stashans, Codoping of $\mathrm{Ni}$ and $\mathrm{Fe}$ in tetragonal $\mathrm{BaTiO}_{3}$, Computational Condensed Matter, 2017, 13, 49-54.

20-. J. Zhang, J. Zhai, X. Chou, J. Shao, X. Lu, $X$. Yao, Microwave and infrared dielectric response of tunable $\mathrm{Ba}_{1-\mathrm{x}} \mathrm{Sr}_{\mathrm{x}} \mathrm{TiO}_{3}$ ceramics, Acta Materialia, 2009, 57, 4491-4499.

21-. Y. Kumar, M. A. Mohiddon, A. Srivastava, K. L. Yadav, Effect of Ni doping on structural and dielectric properties of $\mathrm{BaTiO}_{3}$, IJEMS, 2009, 16, 390-394.

22- A. El Ghandouria, S. Sayouria, T. Lamcharfib, L. Hajji, Effect of strontium on the structural and piezoelectric properties of the sol gel processed barium titanate, J. Ceram Process Res, 2018, 19, 154-170.

23- J. A.Sanjurjo, E.Lopez-Cruz, High-pressure Raman study of zone-center phonons in $\mathrm{PbTiO}_{3}$, Phys. Rev. B, 1983, 28, 25-27. 